\title{
s discursos no discurso
}

\section{do livro-reportagem}

\section{Ariane Carla Pereira 1}

Resumo: Como definir o livro-reportagem? Jornalismo ou Literatura? Não apenas um, nem somente o outro. Um gênero híbrido afinal, soma elementos da literatura e do jornalismo - mas, sobretudo, autônomo. Para refletir um pouco mais sobre esse discurso outro que é o livro-reportagem, proponho, neste artigo, pensar suas especificidades a partir da colocação em cena do discurso relatado. Assim, tenho como objetivo analisar as formas e as funçōes do discurso direto e do discurso indireto em Rota 66 - a história da polícia que mata, do jornalista-escritor Caco Barcellos. Ao tratar do discurso citado não é possível deixar de pensar, também, nos marcadores textuais e tipográficos que acompanham as falas citadas. Além disso, julgo necessário refletir, no corpus definido, os verbos introdutores do discurso alheio. Este estudo evidenciou que o discurso relatado, em Rota 66, é usado para explicitar e/ou contrapor os posicionamentos do jornalista-escritor e da Polícia Militar.

\section{Palavras-chave: heterogeneidade, jornalismo, livro-reportagem.}

\begin{abstract}
How to define a documentary book? Journalism or Literature? Not just one, neither only the other. A hybrid genre after all, it adds up elements of literature and journalism - but, especially, independent. In order to reflect a little longer on this other discourse that is the livro-reportagem, I propose, in this article, to think about its particularities starting from the mise-en-scène of the reported discourse. Therefore, my aim is to analyse the forms and the functions of the direct speech and indirect speech in Rota 66 - a história da polícia que mata, by the writer-journalist Caco Barcellos. On dealing with the reported discourse it is impossible not to take into consideration the textual and typo markers which go with the quoted discourses. Moreover, I judge necessary to reflect, in the selected corpus, on the verbs which introduce the other's discourse. This study demonstrated that the reported discourse, in Rota 66, is used to make explicit and/or contrast the positions of both the writer-journalist and the Polícia Militar.
\end{abstract}

1 Jornalista, mestranda em Letras pela Universidade Estadual de Maringá

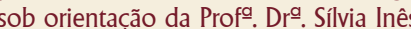
Coneglian Carrillo de Vasconcellos, professora do curso de Jornalismo da Faculdade Sul Brasil (Fasul), Toledo/PR ariane_carla@uol.com.br
A publicação de reportagens em formato de livro, no Brasil, teve início na década de 1970. Obras que, logo, foram chamadas de romances-reportagens. Termo dado, inicialmente, por Ênio Silveira, editor da Civilização Brasileira, a uma 
coleção que, segundo Rildo Cosson, "pretendia recobrir apenas um conjunto de obras baseadas em episódios reais vazados em uma narrativa que adotava contornos ficcionais" (COSSON, 2002: 60).

Porém, a expressão se vulgarizou e passou a denominar "tanto um tipo particular de narrativa que mistura literatura e jornalismo, quanto uma das tendências dominantes na ficção brasileira da década de 1970" (COSSON, 2002: 60). Ou seja, no primeiro caso, quando o caráter literário do romancereportagem é aceito, ele é visto como o representante do terceiro momento da estética e da ideologia naturalista brasileira. Já a visão expressa no segundo caso, não reconhece a apropriação de traços literários pelo romance-reportagem.

Este último ponto de vista é influenciado pela explicação mais comum para o surgimento do romance-reportagem: uma (re)ação dos jornalistas à censura. Porém, essa relação, de acordo com Cosson, precisa ser revista porque existe "um descompasso entre o período de atuação mais forte da censura jornalística, anterior a 1975 , e o período em que se inicia a publicação dos romances-reportagens, posterior a 1975" (COSSON, 2002: 62).

A visão de romance-reportagem como obra naturalista também não é aceita pelo autor citado. Para ele, as duas leituras são parciais e o romancereportagem só pode ser considerado, lido e analisado como um gênero autônomo e híbrido que reúne "a força política do jornalismo com a força poética da literatura" (COSSON, 2002: 70).

Boa definição para um termo que ainda possibilita leituras equivocadas como foi exposto acima. Por isso, é que nos últimos anos muitas das reportagens publicadas em formato de livro passaram a ser chamadas de livros-reportagem. Porém, mesmo essa designação é encarada por alguns estudiosos, a partir da minha perspectiva de jornalista e de lingüista, de maneira limitada. Esse é o caso de Edvaldo Pereira Lima, autor de O que é livro-reportagem, que afirma:

Em síntese: é para isto que serve basicamente o livro-reportagem: para estender o papel do jornalismo contemporâneo, fazendo avançar as baterias de explicações para além do terreno onde estaciona a grande reportagem na imprensa convencional. (LIMA, 1998: 16)

Em meus estudos trato este tipo de narrativa como livro-reportagem. Porém, considerando-o como o gênero autônomo e híbrido de que falou Rildo Cosson. Assim, acredito que o livro-reportagem é, ao mesmo tempo, literatura e jornalismo.

Jornalismo, ou reportagem, porque o jornalista-escritor prima pela

No sentido jornalístico de não se contentar com a versão oficial, de não ficar na superfície, de buscar a notícia onde a maioria das pessoas não a vê ou não quer enxergá-la.

3 do real como um fato, algo que "realmente" aconteceu. E, nesse ponto, julgo necessário explicitar minha visão enquanto pesquisadora na área de lingüística e, também, como jornalista. Assim, acredito que a isenção total é impossivel. Afinal, ao narrar/contar/descrever um fato o que se faz, na verdade, é apresentar uma versão dele: a do jornalista, por mais imparcial que ele pretenda/busque/acredite ser. investigação $\mathbf{2}$, pelo levantamento de informações, por narrar histórias "reais" $\mathbf{3}$, histórias que denunciam alguma coisa que vai/caminha/está errada na sociedade. "Fazer jornalismo é fazer história, a história do cotidiano" (SATO, 2002: 33). Ou seja, o livro-reportagem é jornalismo porque cumpre a função primeira deste que é informar e, através dessa informação, levar a sociedade a se posicionar e a buscar mudanças.

Literatura, ou livro, porque ao contar essas histórias do cotidiano o jornalista-escritor não segue (necessariamente) os paradigmas/as normas do discurso jornalístico. Ou seja, a imparcialidade, a isenção, a neutralidade e a objetividade perseguidas no jornalismo diário podem - e são - deixadas de lado. Assim, ao fazer sua narrativa, o jornalista-escritor abandona o estilo seco, duro 
dos jornais diários e recorre (sem perdas informacionais) a elementos literários. "À literatura cabe fazer com que o recorte da realidade atue como uma explosão que abra uma realidade muito mais ampla. À literatura cabe abrir horizontes" (SATO, 2002: 45).

A partir dessa exposição e contextualização do livro-reportagem como discurso outro, que não é nem simplesmente discurso jornalístico nem apenas discurso literário, proponho-me a pensar a especificidade do livro-reportagem. $E$, assim, julgo que uma das maneiras de se cumprir esse objetivo é analisar o discurso do outro e, para isso, vou descrever lingüisticamente as formas do discurso direto (DD) e do discurso indireto (DI) e caracterizar suas funcionalidades no discurso do livro-reportagem Rota 66 - a história da polícia que mata, de autoria do jornalista Caco Barcellos.

A reflexão sobre o discurso relatado, do outro, no livro-reportagem se mostra importante para perceber como a heterogeneidade, que é constitutiva de qualquer discurso, se constrói nesse gênero discursivo. Afinal, como afirma Indursky, "não é possível conceber um discurso de modo isolado. Um discurso sempre está em relação com outros discursos. [...] Um discurso é heterogêneo porque sempre comporta constitutivamente em seu interior outros discursos" (INDURSKY, 1997: 196).

Concordando com esse posicionamento e pensando a heterogeneidade do livro-reportagem me deparei, logo de início, com uma dúvida. $\bigcirc$ discurso citado, nessas obras e especificamente em Rota 66 - que foi escrito anos depois da ocorrência dos fatos -, é, na verdade, uma reconstituição das falas das personagens 4 e não, especificamente, suas próprias palavras. Nesse caso, me perguntava se esses discursos seriam discursos do(s) outro(s) mesmo ou, apenas, falas do narrador disfarçadas?

Questionamento que me pareceu ter uma resposta clara, simples e, até mesmo, óbvia depois da leitura de alguns autores que se posicionam sobre o discurso relatado. Para Benites "o texto citado, mesmo que literalmente repetido, apresenta-se como uma imagem desprovida de grande parte de seu entorno e adquire, por isso, significado diferente ou até mesmo oposto" (BENITES, 2002: 57). Dessa maneira, segundo a autora, "tanto o discurso direto quanto o discurso indireto podem ser manipulados pelo locutor citante" (BENITES, 2002: 60). Nessa mesma linha de pensamento, Authier afirma que "o discurso direto cita as palavras de (I), enquanto o discurso indireto as traduz; nem o primeiro nem o segundo falam com as palavras do outro" (apud INDURSKY, 1999: 199).

Dúvida esclarecida e tendo como certo que a repetição integral da fala do outro nunca é possível - afinal, a enunciação é única e irrepetível - passei a analisar o aparecimento dos discursos do(s) outro(s) no livro-reportagem. Assim, foi possível perceber que a citação - direta ou indireta - tem formas e funções específicas em Rota 66 e que a primeira é mais utilizada do que a segunda. A tabela abaixo representa a ocorrência dos discursos indireto e direto em cada uma das três partes em que o livro é dividido.

\begin{tabular}{|l|l|l|l|}
\hline ROTA 66 & $1^{\underline{9}}$ parte & $2^{\underline{a}}$ parte & $3^{\mathfrak{a}}$ parte \\
\hline Discurso Indireto & 16 ocorrências & 20 ocorrências & 3 ocorrências \\
\hline Discurso Direto & 102 ocorrências & 108 ocorrências & 112 ocorrências \\
\hline
\end{tabular}


O discurso indireto, para Maingueneau, "só é discurso citado por seu sentido, constituindo uma tradução da enunciação citada. [... Não reproduz um significante, mas dá um equivalente semântico integrado a enunciação citante" (MAINGUENEAU, 2001: 108-109). Ao tratar do DI, Indursky diz que ele "é apresentado como um processo de parafrasagem, vale dizer, de 'versão' que o locutor (L) faz do discurso do outro (I)" (INDURSKY, 1999: 198, grifo da autora).

\section{DI - função 1}

No livro-reportagem Rota 66 esse tipo de discurso citado é usado de

5 Em alguns momentos, mais especificamente na terceira parte do livro, o DI é usado para marcar a voz do outro. Porém, sem a pretensão de mostrar a partir dessa fala o posicionamento desse enunciador. Sem se enquadrar, portanto, em nenhuma das funções específicas por mim percebidas. Por isso, essas ocorrências não foram contadas e não serão estudadas.

6 O jornal paulistano Notícias Populares.

7 Polícia Militar.

8 documento público onde os policiais civis são obrigados a registrar os dados principais dos crimes ocorridos em sua jurisdição, baseados nos relatos das testemunhas" (2003, p.89)

9 , inicialmente, a outras citações para melhor apresentar ao leitor o posicionamento da polícia e, também do jornalista Caco Barcellos em Rota 66. Após essa familiarização com o conteúdo do livro-reportagem me limitarei a apresentar apenas os exemplos para cada função do discurso relatado na obra citada.

10 posicionamento do jornalista-escritor que é contrário ao do delegado. Ao usar "matadores-vítimas" e não, simplesmente, "policiais envolvidos", por exemplo, o autor deixa vazar um alto grau de subjetividade que em nada lembra as recomendações dos Manuais de Redação e dos livros de Técnicas de Reportagem de texto objetivo e imparcial. duas maneiras/formas e com duas funçōes $\boldsymbol{5}$. Uma delas é explicitar o posicionamento do outro, da personagem. E, assim, contrapor esse posicionamento - implícita ou explicitamente - com o do jornalista-escritor (autor/locutor). Posicionamentos esses que são, no mínimo, diferentes ou, mais freqüentemente, contraditórios, antagônicos. Exemplo 1:

As primeiras leituras do NP 6 já revelam que a versão oficial sobre o envolvimento de policiais em crimes de morte geralmente parece um documento de defesa dos matadores. (BARCELLOS: 2003, 89, grifo meu)

O jornalista-escritor Caco Barcellos explica nesse mesmo capítulo O pior do passado - que precisou recorrer ao jornal Notícias Populares para montar um Banco de Dados que tinha como objetivo "conhecer o perfil das vítimas e as circunstâncias em que elas são mortas pela Polícia Militar" (BARCELLOS, 2003: 87). Optou pela leitura do jornal citado, já que seus "pedidos de pesquisa nos arquivos da PM $\mathbf{Z}$ são sempre negados" (BARCELLOS, 2003: 88) e, também, porque:
A maior parte dos casos de pessoas mortas pela Polícia Militar é escrito no NPa partir das informações do Boletim de Ocorrências $\boldsymbol{8}$, ou da Nota Oficial divulgada pelo Serviço de Relações Públicas da PM. Desta maneira, ao ler as notícias de tiroteio envolvendo policiais, consigo reproduzir a versão oficial, com fidelidade, de todos os casos de mortes divulgadas. (BARCELLOS: 2003, 88)

Assim, voltando ao Exemplo 1, podemos distinguir dois locutores (como propõe Authier):

$\mathrm{I}$ = arquivo do NP = versão oficial = versão das testemunhas que são os próprios policiais envolvidos: os policiais matam para se defender $\mathbf{9}$.

A primeira frase escrita no Boletim de Ocorrência define a natureza do inquérito: resistência à prisão seguida de morte. [...] no espaço destinado à vítima, o delegado titular da 15ํㅡㄹ Delegacia, Hugo Ribeiro de Melo, escreve o nome do sargento José Felício Soares. Na seqüência relaciona os outros quatro PMs da Rota 66. [...] Em seguida, o delegado começa a narrar o histórico dos fatos, baseado no testemunho dos matadores-vítimas 10 :

[...] ... Na rua Argentina, por volta das 3h40, os ocupantes do Volks começaram a fazer disparos contra a viatura, tendo os policiais reagido. Na rua Argentina, esquina com Alasca, o Volks bateu em um poste (...) Os ocupantes desceram do carro atirando. Todos os policiais usaram armas diante da séria resistência oferecida pelos perseguidos. Os três elementos saíram feridos. Em seguida, chegava a Rota 17, que transportou os feridos para o Hospital das Clínicas onde faleceram... 
...No Volks foram encontradas três porções de maconha. Na rua foram recolhidas três armas usadas pelos ocupantes do automóvel... (BARCELLOS: 2003, 79-80, grifo do autor, grifo meu)

\section{$\mathrm{L}=$ autor $=$ jornalista-escritor $=$ versão que é resultado da investigação dos crimes: os policiais são matadores e passam da posição de vítima para a posição de acusados.}

Instantes depois do assassinato, ao chegar à esquina da Argentina com a Alasca, o oficial da Rota-Comando, tenente Eli Nepomuceno, de 21 anos, se revela um profissional totalmente despreparado para a função. Os corpos dos rapazes estão sendo arrastados do Fusca para o compartimento de presos da Rota 17, numa violação do local do crime que deveria ser totalmente preservado. (BARCELLOS: 2003, 75, grifos meus para destacar as subjetivações, o posicionamento do jornalista-escritor)

Basta contar os tiros que atingiram o carro para concluir que a intenção dos PMs não era a de evitar a morte dos rapazes. Os dois pára-brisas estão estilhaçados, os vidros da janela do motorista e o lateral traseiro também. $\underline{\text { São } 21 \text { marcas de bala, a maioria }}$ na parte superior do Fusca, o que indica a vontade de matar.

Os ferimentos nos corpos são ainda mais reveladores. $O$ sangue escorre por 23 perfuraçōes de balas, a maior parte em regiōes vitais, como o coração e a cabeça. A pressa em socorrer só ocorre, de fato, na retirada dos corpos do local do crime. (BARCELLOS: 2003, 75-76, grifos meus para destacar as subjetivações, o posicionamento do jornalista-escritor)

Os plantonistas do pronto-socorro do Hospital das Clínicas são avisados da chegada de três jovens gravemente feridos. Os médicos correm à entrada. Os corpos ainda estão na viatura quando eles constatam que não há nada o que fazer. Sugerem que sejam levados direto ao Instituto Médico Legal. [... Depois de uma rápida discussão, os médicos admitem a entrada dos corpos à enfermaria, mas observam, em cada uma das fichas, que os três já eram cadáveres ao dar entrada no hospital. (BARCELLOS: 2003, 66-67, grifos meus para destacar as subjetivações, o posicionamento do jornalista-escritor)

Preservar o local do crime para os matadores significa não alterar somente aquilo que possa ajudá-los no inquérito. [... A droga teria sido encontrada dentro do Fusca quando o soldado Cláudio Cândido fazia o papel de perito. Há uma estranha dúvida sobre a embalagem da maconha. O sargento José Felício Soares afirma ter feito a entrega do achado ao tenente Nepomuceno com três pequenas porçōes. O tenente diz que a droga estava dentro de um saco plástico. $\underline{O \text { delegado não liga para a }}$ incoerência. Pergunta sobre as armas. Segundo a versão dos matadores, estavam ao lado dos corpos dos rapazes, no asfalto.

Se a história que os PMs estão contando na delegacia é verdadeira, nada justifica a retirada irregular das armas da esquina do crime, antes da chegada da perícia. A não ser dificultar o início de uma possível investigação científica.

A outra hipótese é a que estejam mentindo: armas e maconha fazem parte de uma farsa, uma armação para incriminar os mortos. (BARCELLOS: 2003, 80-81, grifos meus para destacar as subjetivações, o posicionamento do jornalista-escritor)

\section{Exemplo 2:}

No dia 7 de agosto de 1984, Rony e seus companheiros de patrulhamento foram denunciados pela morte de um rapaz desconhecido, envolvido numa briga de rua. Os PMs afirmaram que ele foi morto em tiroteio, depois de reagir à prisão. $O$ exame da arma apreendida, como se tivesse sido usada pela vítima, revelou anomalias nos seus sistemas de percussão e repetição. Segundo o laudo dos peritos, esses defeitos impediam a realização de disparos. Três testemunhas garantiram em seus depoimentos que a vítima não estava armada. O estudante Wagner Moreno, preso junto com o rapaz, disse que a causa da morte foi o disparo aparentemente acidental da arma de um PM. (BARCELLOS: 2003, p.182, grifos meus) 
11 Data da morte dos três rapazes da fusca azul - caso Rota 66.
Este segundo exemplo da primeira função percebida em Rota 66 foi retirado do Capítulo 13, Matador de inocentes. Este título é uma referência ao soldado Rony Jorge da Silveira Paulo, um dos quinze policiais envolvidos no caso Rota 66. "Contabilizei o seu envolvimento em quatro assassinatos de jovens antes de abril de $75 \mathbf{1 1}$. Constatei também que após essa data ele continuou matando com ainda maior freqüência: identificamos mais nove pessoas mortas por Rony após o caso Rota 66" (BARCELLOS, 2003: 176).

Dessas treze mortes, as circunstâncias de como ocorreram quatro delas são relatadas por Caco Barcellos: a do sósia de Roberto Carlos, José Mendes de Oliveira (BARCELLOS, 2003: 173); as de Jorge Ribeiro e Augustinho Nilton Candeias (BARCELLOS, 2003: 178); e a de um rapaz desconhecido (BARCELLOS, 2003: 182). É a essa última que se refere o exemplo 2. Assim, nesse segundo trecho usado para exemplificar a primeira função do discurso indireto em Rota 66, é possível perceber mais nitidamente os posicionamentos antagônicos dos dois locutores:

I = os PMs envolvidos no "tiroteio" do dia 7 de agosto de 1984 = versão oficial: os policiais, assim como no exemplo anterior, mataram para se defender ("foi morto em tiroteio, depois de reagir à prisão").

$$
\mathrm{L}=\text { peritos }=3 \text { testemunhas }=\text { Wagner Moreno }=\text { jornalista-escritor que }
$$
coloca em cena as vozes dessas pessoas para demonstrar seu próprio ponto-devista: laudo técnico e testemunhos são provas de que policiais mataram e não assumiram sua responsabilidade mesmo com o tiro tendo sido acidental.

\section{DI - função 2}

O jornalista-escritor Caco Barcellos, também, utiliza o discurso indireto no livro-reportagem analisado com um segundo objetivo: introduzir o discurso direto. Dessa maneira, o DI situa o leitor, e o DD reforça, vivifica o que foi relatado. Exemplo 3:

O promotor João Benedito de Azevedo Marques denunciou 24 policiais, inclusive Matínez e Filó, por não acreditar na versão oficial. Os policiais alegaram que Daniel tinha duas armas e resistiu a prisão, provocando o tiroteio. $\underline{\bigcirc \text { promotor }}$ conclui que houve excesso por parte dos policiais, que agiram sem dar nenhuma chance de defesa à vítima.

... interessante notar que segundo os peritos o revólver Castelo que teria sido encontrado com Danilo não tinha condições de funcionamento e, portanto, não poderia ter sido utilizado para a efetivação dos disparos alegados pelos policiais, enquanto o revólver marca "Rossi" estava com o número raspado, o que não deixa de ser extremamente suspeito. (BARCELLOS, 2003: 197-198, grifo do autor, grifos meus).

Exemplo 4:

O vidraceiro Valdevino, empregado da vidraçaria Idramar, é casado, tem uma filha e a mulher está grávida de quatro meses. A polícia já o prendeu várias vezes como suspeito sem jamais ter provado nada contra ele. Torturado em outras ocasiões, Valdevino tem muito medo dos policiais, fato que revela logo no início da tortura:

Eu confesso qualquer coisa. Mas pare com isso, pelo amor de Deus! 
Os exemplos 3 e 4 colocaram em cena não apenas o $\mathrm{Dl}$, que era abordado naquele momento, como também o discurso direto - tipo de discurso relatado que é predominante em todas as 350 páginas do livroreportagem analisado, como já foi dito anteriormente. E é sobre o DD que vou me deter a partir daqui.

O discurso direto, segundo Indursky, é "considerado usualmente como a citação textual do discurso de um outro locutor (I)" (INDURSKY, 1999: p.198). Porém, a transparência deste tipo de discurso relatado, a impressão de que a recuperação da fala do outro é fiel, não tendo sofrido transformações, é apenas uma ilusão. Afinal, ao trazer o discurso do outro para dentro de seu discurso, o enunciador está criando uma nova situação enunciativa, assim como o faz no discurso indireto. Ou seja, nada garante que a palavra primeira é preservada e não distorcida.

O DD é uma armadilha, uma ficção que remete ao conflito constitutivo do DD: (L) apaga-se diante de um enunciado textualmente reproduzido e, ao mesmo tempo, [...] corta todos os vestígios da situação de enunciação que está sendo relatada, na qual o enunciado se inscreve e é dotado de sentido. (AUTHIER apud INDURSKY, 1999: p. 199)

Nesse sentido, Maingueneau afirma que o DD "simula restituir as falas citadas e se caracteriza pelo fato de dissociar claramente as duas situações de enunciação: a do discurso citante e a do discurso citado" (MAINGUENEAU, 2003: p.140, grifo do autor). Uma segunda reflexão desse mesmo autor sobre o discurso direto mostrou-me que as dúvidas iniciais sobre o discurso citado no livro-reportagem, de fato, não se justificavam:

O discurso direto não relata necessariamente falas pronunciadas efetivamente. [...] Mesmo quando o DD relata falas consideradas como realmente proferidas, trata-se de uma encenação visando criar um efeito de autenticidade: eis as palavras exatas que foram ditas, parece dizer o enunciador. (MAINGUENEAU, 2003: 141, grifos do autor)

E é justamente este "efeito de autenticidade" que, acredito, justifica a grande diferença entre o número de citações por discurso direto e por discurso indireto no livro-reportagem Rota 66. Afinal, como foi dito anteriormente, esse tipo de livro, por ser reportagem, é jornalismo e, como tal, ao trazer o discurso do outro "fielmente" reforça a idéia de que conta/relata/narra, apenas, a verdade. Hipótese que ganha mais força com uma nova retomada de Maingueneau. Afinal, segundo este autor, a escolha do DD está ligada ao gênero do discurso em questão já que com este modo de relatar o discurso do outro pode-se:

\footnotetext{
- criar autenticidade, indicando que as palavras relatadas são aquelas realmente proferidas;

- distanciar-se: seja porque o enunciador citante não adere ao que é dito e não quer misturar esse dito com aquilo que ele efetivamente assume; seja porque o enunciador quer explicitar, por intermédio do discurso direto, sua adesão respeitosa ao dito [...]; - mostrar-se objetivo, sério. (MAINGUENEAU, 2003: 142).
} 
Esses quatro efeitos - já que o segundo divide-se em dois - que podem ser obtidos com o discurso direto são percebidos em Rota 66. Autenticidade ao recorrer ao DD o jornalista-escritor, sempre, quer demonstrar que está falando a verdade; não-aderência ao dito - ao contrapor dois posicionamentos, o de Barcellos e o da polícia; aderência ao dito - ao inserir citações que confirmam o pensamento de que a polícia mata e não para se defender; e seriedade - o DD é utilizado pelo autor como para, também, dizer: "essas falas não são minhas, sinal de que não digo sozinho". Assim, vocês - leitores - podem confiar em mim. Dessa maneira, após o estudo do DD, passo a análise das formas e funçōes que este tipo de discurso relato assume ao ser empregado por Barcellos no livroreportagem em questão.

\section{DD - função 1}

A primeira função do DD em Rota 66 é dar veracidade à narrativa e credibilidade ao escritor-jornalista. Assim, Caco Barcellos, recorre ao discurso relatado em forma direta após apresentar informaçōes e/ou fazer comentários para, assim, conferir verdade ao que é dito. Ou seja, mostrar-se objetivo e sério, nas palavras de Maingueneau. Exemplo 5:

Um boletim interno da Rota, de número 93, assinado em 29 de junho de 1982, é uma das provas que encontrei de que os comandantes incentivam a ação dos matadores. $\mathrm{O}$ boletim se refere ao envolvimento de Rony Jorge numa perseguição a quatro jovens suspeitos de serem criminosos. Durante a fuga teria havido um tiroteio cujo desfecho foi o capotamento do carro dos jovens. Mesmo depois do acidente, segundo a versão dos PMs, eles teriam resistido a prisão a tiros. Depois do suposto tiroteio, os jovens foram levados feridos ao Pronto-Socorro de Vila Prudente, onde dois morreram. $O$ desfecho do caso levou o comandante da Rota a fazer um elogio emocionado ao soldado Rony Jorge.

...Parabéns, companheiro, demonstrou coragem, tirocínio policial, consciência do dever e experiência no serviço da Rota, exaltando-a perante a população bandeirante, fazendo-se assim merecedor dos cumprimentos deste comando... (BARCELLOS, 2003: p.185, grifo do autor, grifos meus para destacar o comentário do jornalista escritor).

\section{Exemplo 6:}

Dias depois, na mesma semana, os PMs Francisco Júnior, Walter Cipolli e Wanderley Alessi, em depoimento secreto nas dependências do Serviço Reservado da Polícia Militar, confessaram que não houve tiroteio. Pixote não disparou nenhum tiro. Depois do fuzilamento, o próprio sargento Francisco providenciou a simulação de tiroteio. Ele pegou a arma apreendida, como se fosse de Pixote, e disparou quatro tiros para o alto, de dentro da viatura, a caminho da delegacia de Diadema. Essa prática não é rara entre seus colegas de farda. Tem até nome próprio, fazer a arma, revelado por Francisco na sua confissão.

Fizemos a arma, antes de saber quem era o cara. (BARCELLOS, 2003: 311, grifo do autor, grifo meu para destacar comentário, feito após apresentação de informaçōes, que vai ser confirmado pela inserção da fala do policial)

\section{DD - função $2 a$}

Uma segunda função do discurso direto no livro-reportagem analisado é dar dinâmica à narrativa. E essa agilidade é conferida à Rota 66 de duas maneiras. Na primeira delas, menos freqüente, o DD é usado para provocar uma quebra, uma ruptura, no que vinha sendo dito. Assim, o jornalista-escritor pode introduzir novos fatos, novos elementos, e dar prosseguimento a narrativa. Exemplo 7: 
A perseguição aos três rapazes ricos do Fusca azul é motivo de cobertura especial em quase todos os jornais do país. A maioria das reportagens tem um tom coerente de denúncia. Narra minuciosamente toda a trajetória da perseguição, desde o momento em que os rapazes foram vistos pela primeira vez pelos homens da Rota 13.

_É a polícia! Mãos na cabeça!

Os três rapazes estavam em volta do Puma de Roberto Veras quando perceberam a Veraneio cinza se aproximando na escuridão, devagar, motor em marcha lenta... (BARCELLOS, 2003: 34).

\section{Exemplo 8:}

De toda a turma, Augusto é quem melhor conhece Pancho na intimidade. Costuma criticar o lado brutamontes do amigo, na opinião dele, uma tentativa de esconder a insegurança de um jovem carente de afeto na família. Depois de ajudar a tirar 28 espinhos do corpo de Pancho, Augusto conseguiu convencê-lo de que a rivalidade com Gomalina estava gerando, com freqüência, atitudes inconseqüentes. Propôs uma trégua, que foi aceita. E consolidada por volta da meia-noite, quando decidiram lanchar no Hamburguinho, junto com Francisco Noronha.

Não estou gostando dessa noite, minha querida. Sabe onde eu queria estar agora? A 320 quilômetros daqui, ao seu lado.

O telefonema à namorada Xaxá, que mora no interior de São Paulo, é revelador da insatisfação de Augusto com a vida na capital... (BARCELLOS, 2003: 40)

\section{$D D$ - função $2 b$}

A segunda maneira do jornalista-escritor empregar o discurso direto com o objetivo de dar dinâmica e agilidade à narrativa é a mais freqüente em todo o livro-reportagem analisado. Essa forma/função é recorrente porque, acredito, é assim que Barcellos divide com o(s) outro(s) a responsabilidade de contar os crimes praticados por policiais militares conferindo, dessa maneira, credibilidade a sua história. E isso é possível porque o dizer do outro funciona como uma prova do que o autor de Rota 66 está dizendo.

Além disso, ao recorrer ao discurso relatado, o jornalista-escritor não precisa, em todos os momentos, fazer afirmações categóricas no intuito de convencer o leitor. Ou seja, essa função é repassada, deixada por conta de dizeres outros - que podem ser de familiares das vítimas, de sobreviventes, peritos, médicos ou dos próprios policiais - que explicitam de que lugar cada um - inclusive Barcellos - fala. Isto é, o discurso relatado coloca em cena os posicionamentos favoráveis ou contrários - não apenas de quem realmente proferiu o dito mas, também, do jornalista-escritor - às mortes que são citadas no livro-reportagem. $\bigcirc$ que permite que o leitor também tome partido - ou seja, conclua se a polícia mata para se defender dos bandidos ou mata por matar independentemente de quem seja a vítima. Exemplo 9:

Neste momento, os soldados dos fusquinhas da Radiopatrulha continuam envolvidos na caçada aos três rapazes. Lurian Ferreira, da RP 1528, e mais três motoristas de RPs continuam se esforçando em uma corrida pelas ruas próximas, na esperança de chegar na frente ao local do tiroteio. A vantagem é de Lurian, que usa a esperteza ao entrar na Alasca pela contramão. Chega na esquina da Argentina alguns segundos antes das outras RPs. Revólver engatilhado, ele se joga no gramado da calçada e se posiciona para o ataque. $O$ motorista da Rota 17 manobra de ré, para levar os rapazes ao hospital. Quase o atropela. O soldado Lurian ainda se arrasta ao ouvir o comentário de alguém que está examinando as grandes manchas de sangue no asfalto.

Três mortes numa única noite. Isso vai dar prêmio! O comando vai adorar. (BARCELLOS, 2003: 65) 
Na maca ao lado, o desconhecido 2350 é João Augusto Diniz Junqueira. Guazzelli controla o choro. Sente o corpo todo tremer. Ele nunca tinha visto uma pessoa morta. Agora é obrigado a examinar o cadáver de seu melhor amigo. O funcionário o orienta a encontrar os pontos de entrada dos tiros.

- Dois no peito, um aqui nesse braço. Tem tiro na nuca, veja só... E um lá embaixo, na sola do pé. E tem mais! Rota é Rota, garotão. Se a gente procurar bem sempre encontra mais um tiro. Procura aí... (BARCELLOS, 2003: 71)

Afirmei anteriormente que a citação na forma de discurso direto tem predomínio em Rota 66, assim como essa última função do DD é preponderante. Exatamente por isso, opto por oferecer um número maior de exemplos. $\mathrm{O}$ a seguir é o de número 11:

\section{2}

Diante de um Conselho de Justiça Militar, formado por um juiz civil, dois majores e dois tenentes da PM, os matadores foram julgados inocentes. A reação da mãe de Francisco Noronha no Tribunal é de revolta:

Na rua, venceu a brutalidade dos covardes. A vitória aqui é da farsa e da hipocrisia.

Dona Maria Junqueira, mãe de Augusto, recebe o veredicto com indignação:

É ridículo, é vergonhoso. Só faltou o júri dar um troféu de honra ao mérito aos matadores do meu filho.

A viúva espanhola Maria Del Fuentes Consuelo Medeiros de Pierre, mãe de Pancho, não se conforma com a impunidade.

- Se a lei fosse cumprida nesse país, meu filho jamais seria morto. Muito menos eu teria que assistir a esse júri tão deprimente. (BARCELLOS, 2003: 117-118)

\section{Exemplo 12:}

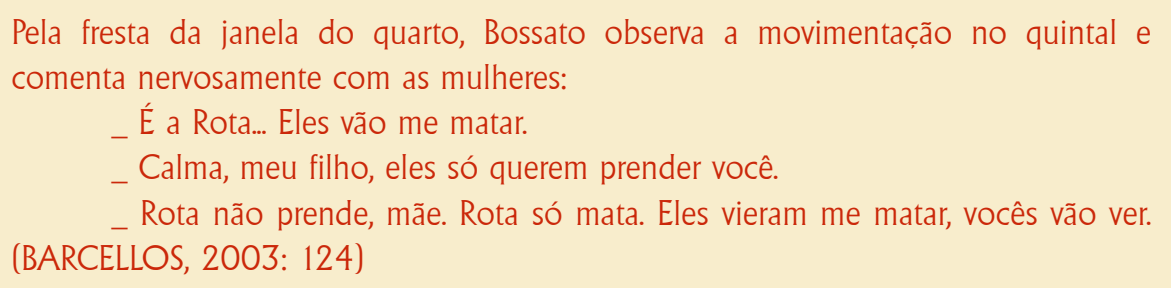

As quatro citações de Rota 66 apresentadas acima como exemplos para essa segunda função/forma do DD no livro-reportagem em análise colocam em cena pessoas diferentes, com posicionamentos diferentes que são explicitados por seus discursos. Falas que são recuperadas pelo jornalista-escritor para, mesmo que implicitamente, mostrar que o posicionamento assumido por ele é o verdadeiro e, assim, conquistar o leitor para a sua causa. Retomo as falas desses exemplos para evidenciar minha afirmação:

Exemplo 9: "Três mortes numa única noite. Isso vai dar prêmio! $\bigcirc$ comando vai adorar". O DD coloca em cena o posicionamento de um PM para mostrar o pensamento generalizado dos membros da Rota perante as mortes. $\mathrm{Ou}$ seja, o discurso relatado demonstra que, para esses policiais militares, eficiência é sinônimo de eficácia - quanto mais pessoas forem mortas, mais os policiais da Rota estão "cumprindo seu dever".

Exemplo 10: "Dois no peito, um aqui nesse braço. Tem tiro na nuca, veja só... E um lá embaixo, na sola do pé. E tem mais! Rota é Rota, garotão. Se a gente procurar bem sempre encontra mais um tiro". A fala é de um funcionário do 
Instituto Médico Legal, isto é, de uma pessoa que, pela sua profissão, está, rotineiramente, em contato com pessoas mortas pelos policiais da Rota e, por isso, está autorizada a afirmar que as vítimas dos "policiais-matadores" nunca são mortas por um único tiro e, sim, são vítimas de "fuzilamentos" - palavra esta usada com freqüência por Barcellos ao descrever as circunstâncias das mortes relatadas no livro-reportagem.

Exemplo 11: "Na rua, venceu a brutalidade dos covardes. A vitória aqui é da farsa e da hipocrisia"; "É ridículo, é vergonhoso. Só faltou o júri dar um troféu de honra ao mérito aos matadores do meu filho"; "Se a lei fosse cumprida nesse país, meu filho jamais seria morto. Muito menos eu teria que assistir a esse júri tão deprimente". Indignação. Esse é o sentimento refletido pelas falas das mães dos três rapazes mortos. Indignação pela morte injustificada dos filhos. Indignação pela ação dos PMs da Rota que para elas não são policiais e sim matadores - posicionamento similar ao do autor do livro-reportagem que em muitos momentos se refere aos membros da Rota como "policiais-matadores". E é essa indignação - compartilhada pelas mães das vítimas e por Barcellos - que o jornalista-escritor quer despertar, também, nos leitores ao colocar em cena esses relatos.

Exemplo 12: "Rota não prende, mãe. Rota só mata. Eles vieram me matar". O dizer de Bossato evidencia a imagem que parte da população tem dos policiais militares integrantes da Rota. Ou seja, são matadores. Imagem que é reforçada com o relato posterior da ação dos PMs e com a morte de Bossato pelos policiais como ele mesmo previa em sua fala. Assim, Barcellos - mais uma vez - recorre ao discurso do outro para confirmar seu posicionamento e, dessa maneira, convencer aos leitores de que a "Rota não prende. Rota só mata".

\section{DD - função 3}

Os diálogos são o terceiro grupo de discurso direto em Rota 66. 0 jornalista-escritor recorre a eles com o objetivo de contrapor dois posicionamentos. Assim, os diálogos têm como função colocar em cena P1 (posicionamento 1) que é igual ao posicionamento de Caco Barcellos - mas não apenas dele, de todos que, como ele, acreditam que a PM age (e nesse caso, agir significa matar) indiscriminadamente e tem como alvo preferencial pessoas pobres - e pobre para os policiais da Rota é sinônimo de vagabundo, bandido; e o de P2 que é igual ao posicionamento da polícia e das pessoas que julgam os policiais como homens que só matam para se defender e defender a sociedade (e desta estão excluídas as pessoas das classes sociais de menor poder aquisitivo, moradoras da periferia). Esses diálogos podem ser entre P1 e P2, como nos exemplo 13 e 14, e entre P1 e P1, como nos exemplos 15 e 16.

Exemplo 13:

Durante a semana fui testemunha de cenas de injustiça, abuso de poder, covardia. Minha reação me trouxe problemas de todos os lados. Um deles foi com o próprio fotógrafo, um profissional experiente em cobertura policial.

- Os soldados estão invadindo o barraco aos pontapés e tu não estás fotografando. Por que não?

Porque não é importante. Cuide do seu trabalho que eu cuido do meu, tá legal?

Como não. Deixaste de registrar uma invasão a domicílio. Isto é crime.

Crime foi o assassinato do major.

- Se um dia fizerem isso na tua casa, vais gostar também?

Casa não é barraco. Isso aqui é esconderijo de bandido, vale tudo. (BARCELLOS, 2003: 51) 
P1 $=$ Barcellos $=$ morador de barraco é um cidadão como qualquer outro e, por isso, a polícia não pode invadir essas casas sem autorização da justiça. Ao fazer isso os policiais estão cometendo um crime. Ou seja, os Pms estão agindo indiscriminadamente.

P2 = fotógrafo $=$ policiais da Rota $=$ barraco não é casa; morador de barraco não é cidadão é bandido. E nesse caso, tudo é permitido, a ação é em legítima defesa.

Exemplo 14:

Para os moradores da favela, a cena faz parte da rotina de brutalidade. Só os mais atentos notam: eles estão especialmente agitados esta noite. Um soldado foi morto dias atrás, um cabo se feriu nesta tarde em um confronto com assaltantes. Agora os matadores querem se vingar em alguém da favela Heliópolis. De preferência um ladrão. Os negros são os mais visados. $\bigcirc$ motorista breca. A Veraneio se arrasta 2, 3 metros. As portas se abrem. Os matadores avançam contra o servente de obra Francisco Pedro da Silva, de 18 anos, que está voltando a pé do trabalho.

_ Pode segurar que é esse aí... - grita o sargento. Francisco.

_ Cadê as armas? - exige o soldado depois de dar um tapa na cara de

Em seguida puxa-o pela corrente do pescoço em direção a uma obra, enquanto os dois colegas fardados esmurram suas costas.

- Por que correu, vagabundo? - pergunta Maurício, que o empurra com um pedaço de pau e ameaça bater.

Não corri. Estou afegante porque caminhei muito do ônibus até aqui explica Francisco com segurança.

A equipe examina os documentos de Francisco. Carteira de trabalho assinada, certidão de nascimento... convence. $\bigcirc$ tipo de conversa também não é a de um malandro. Resolvem liberar.

_ Se não correu, vai correr agora... Corre, desgraçado! - grita o soldado.

- Não corro, não sou ladrão - retruca o operário, já indo embora. (BARCELLOS, 2003: 212-213)

P1 = Barcellos $=$ Francisco Pedro da Silva $=$ trabalhador independente da idade, da cor, da classe social, do lugar onde mora não tem motivos para temer a polícia = vingadores, ou seja, pessoas que agem indiscriminadamente.

P2 = policiais da Rota = morador de favela e negro é ladrão e, por isso, pode ser parado a qualquer momento sem ser considerado inocente o que justifica empurrões, tapas e, até mesmo, sua morte.

Exemplo 15:

Por força do trabalho e pelas histórias de minha vida pessoal, já conheço bem os métodos de ação das polícias militares, criadas poucos anos antes pela ditadura em vários estados do país. $\bigcirc$ chefe da editoria de polícia da Folha da Manhã, meu amigo Licínio de Azevedo, também, está surpreso.

_ Os garotos são da fina flor da sociedade, famílias tradicionais. $\bigcirc$ bairro deles é o mais rico... Como explicar isso, Caco?

_ É estranho. A Rota foi criada para combater guerrilheiros. Faz tempo que a guerrilha acabou...

_ Talvez sejam de alguma nova organização... Licínio?

Mas o motorista do Fusca tem 17 anos. Guerrilheiro com essa idade,

- Não podemos esquecer que ultimamente os PMs andam caçando criminosos comuns...

_ Mas só criminoso pobre. Rico jamais! (BARCELLOS, 2003: 33) 
P1 = Barcellos $=$ Licínio de Azevedo $=$ Rota deixou de cumprir sua função (combater a guerrilha) e passou a matar criminosos comuns. E, nesse caso, qualquer pessoa pobre é suspeita.

Exemplo 16:

\footnotetext{
Neste caso de Pixote, como o caminho técnico já está praticamente inviabilizado, o depoimento das testemunhas adquire maior importância na procura da verdade. Explico isso para Helena, mais aliviada pela chegada do marido Serginho. Depois de sair do trabalho, ele evitara voltar para casa, por medo de sofrer represálias da polícia. Agora Serginho ouve a mulher contar a morte de seu melhor amigo. Eles permitem que eu grave o relato de Helena.

Ouvi um barulho de um pontapé na porta e logo depois o soldado avisar que achou Pixote, que estava embaixo da cama da vó.

E Pixote falou alguma coisa?

Primeiro gritou: "Ai, ai, ai"...

E depois?

Fez um apelo, desesperado.

Qual foi?

"Pelo amor de Deus, não me mate, eu tenho uma filha pra criar!"

E os PMs disseram alguma coisa?

Dispararam sete, oito tiros. (BARCELLOS, 2003: p.306)
}

P1 $=$ Barcellos $=$ Helena e o marido Serginho $=$ polícia mata por matar e não para se defender. Afinal, que perigo oferece um pessoa acuada?

\section{DD - marcas textuais e tipográficas}

Após evidenciar as formas e as funções do discurso direto é preciso, ainda, tratar sobre a forma como esse tipo de discurso citado é introduzido no livro-reportagem Rota 66. Afinal, segundo Maingueneau (2003: 143), o $\mathrm{DD}$, em textos escritos, deve, necessariamente, vir acompanhado de marcas textuais - identificação do locutor e verbo dicendi (ou seja, verbos que indicam enunciação) - e/ou de marcas tipográficas - como dois pontos, travessão, aspas e itálico.

Essa marcação/delimitação do discurso outro segue uma regularidade em todo o livro-reportagem analisado. Isto é, o autor de Rota 66, ao escrever, optou por introduzir a citação na forma de discurso direto usando, na maioria das vezes, apenas o travessão como marca tipográfica. Assim, das 102 ocorrências de DD, na primeira parte, apenas 22 não são introduzidas somente por travessão; na segunda parte, são 24 citações que não seguem essa regularidade num total de 108; e, na terceira e última parte, ocorre a maior parte das exceções percebidas: 58 em 112 citações em discurso direto.

Essa decisão por não explicitar textualmente os elementos introdutores do discurso direto, acredito, refletem o perfil do autor e, também, o perfil da obra. Afinal, além de ser livro é reportagem, e antes de ser escritor ele é jornalista e como tal deve ir direto ao fato, ao essencial. Regularidade esta que é facilmente percebida no exemplo seguinte (17): 
O motorista do Fusca azul, Francisco Noronha, sem tirar o pé do acelerador, reduz da quarta marcha para a terceira, em seguida para a segunda, e, ao girar o volante à esquerda, a roda dianteira bate no canteiro divisor de pista. Sem perder o controle, imediatamente ele gira à direita e segue em direção à calçada oposta. Sobe o meiofio. Quase atropela um grupo de jovens, que tenta proteção junto ao muro. Ao desviar deles, por sorte, bate com a traseira em um poste na esquina. O Fusca se alinha sobre a calçada da Brasil, com a frente apontada para a direita, que está livre para a fuga.

_ Atenção, tigrão. Prioridade na rua Maestro Chiafarelli. É Maestro Chiafarelli, QSL, tigrão? A prioridade agora é Maestro Chafarelli. Três elementos Fusca azul. QSL. QSL, tigrão? Câmbio.

Os cinqüenta tigres estão espalhados pela cidade, cinco em cada uma das dez Veraneios cinza. Tão logo ouvem a ordem da Central de Operações, via rádio, começam a voar baixo em direção ao Jardim América. (BARCELLOS, 2003: 15-16)

Além de possibilitar a percepção do que foi dito anteriormente sobre a principal regularidade das marcas introdutoras do DD em Rota 66, o exemplo acima também revela que é bastante freqüente a supressão das frases introdutoras contendo a identificação de quem fala, principalmente, e o verbo de apresentação do dizer outro.

A designação é mais freqüente nas citações onde são colocados em cena dois, ou mais, locutores. Já os verbos dicendi são utilizados quando Barcellos quer mais do que simplesmente apresentar a fala, isto é, quando o objetivo é fazer o leitor vivenciar o momento da enunciação. Afinal, esses verbos especificam o tipo de fala e traduzem atitudes, intenções, estados emocionais do locutor (RISSO, 1978). Especificidades que podem ser percebidas no próximo exemplo (18):

Depois da cena de ciúme, lara está decidida a sair do carro e não dá muita importância ao último diálogo deles, onde Noronha revela que - se tudo acontecer como está combinado com os amigos - esta noite, para ele, ainda será longa e agitada.

_ Ô, meu! Você vai dormir cedo ou ainda vai pra gandaia?

_ Vou ao Paulistano. Tem um lance aí. Periga pintar um gravador. Já temos um canal pra vender em Santos, coisa do Pancho.

Não é barra-pesada, não, Noronha?

Não se preocupe, será a última vez. (BARCELLOS, 2003: 20)

A identificação do locutor (e, por vezes, também do interlocutor) e/ou o verbo dicendi podem anteceder a citação em discurso direto como no exemplo anterior ou virem após as falas citadas com no exemplo a seguir (19):

Os matadores têm pressa. Deixam os rapazes no plantão para o delegado averiguar se são pessoas condenadas ou não pela Justiça e voltam à Veraneio, onde os dois soldados já estão ansiosos.

- Vamos deixar esses dois aí também. Eu posso levá-los - sugere Rotundo.

_ Como é, você está mijando? Quer adoçar a ocorrência? - retruca Maurício sem esconder a irritação.

_ Puta cagada. Está cheio de testemunhas aí. Não há motivo pra isso - alerta Rotundo sem muita convicção.

_ Liga essa merda e vamos embora, porra - ordena Maurício.

_ Fica frio, Rotundo - acalma Matínez, pondo fim na discussão.

_ Temos que ir atrás dos cabritos - lembra Maurício, referindo-se à necessidade de procurar armas particulares para simular um tiroteio com os menores. (BARCELLOS, 2003: 218) 
Na segunda metade do livro-reportagem analisado, o jornalistaescritor recorre, algumas vezes, a um segundo marcador gráfico do discurso direto: os dois pontos. $O$ que pode ser percebido neste exemplo de número 20:

Do primeiro ao último minuto o sargento Antônio Bueno assistiu ao julgamento aos prantos, sem nada falar. Resistiu calado até às ironias dos colegas. Logo após o veredicto do júri, o tenente Scobar, amigo dos matadores, foi um dos que mais o provocaram:

Se conforma, Bueno. Seu filho era bandido, tinha que morrer! (BARCELLOS, 2003: 235)

Não é possível estudar o discurso citado - direto ou indireto sem falar dos verbos dicendi. Afinal, eles são um aspecto integrado e importante na estrutura da citação. Pois, além do introduzirem a fala do outro, eles também têm - como disse acima - uma função expressiva. Por isso, é que os manuais de redação dos jornais determinam que os jornalistas priorizem a utilização de alguns verbos e não usem outros. O verbete "verbos declarativos" do Novo Manual da Folha de S. Paulo recomenda:

\footnotetext{
Use apenas para introduzir ou finalizar falas dos personagens da notícia, não para qualificá-las ou para insinuar qualquer opinião a respeito delas. Evite, assim, verbos como admitir, reconhecer, lembrar, salientar, ressaltar, confessar, a não ser quando usado em sentido estrito. Nenhum deles é sinônimo de dizer. Ao empregá-los de modo inadequado, o jornalista confere caráter positivo ou negativo às declarações que reproduz, mesmo que não tenha a intenção. Use de preferência os verbos dizer, declarar e afirmar, os mais neutros. (NOVO MANUAL DE REDAÇÃO da Folha de $S$. Paulo, 1994: 116)
}

Recomendação fundamentada na preocupação com a objetividade. Pois, com exceção de dizer que aparenta neutralidade, os outros verbos delocutivos expressam, segundo Benites (2002: 112), pressupostos (por exemplo: revelar, repetir, replicar, concluir, reconhecer, confessar, ordenar, suplicar); caracterizam a forma ou o tom em que se dá a fala (como sussurrar, murmurar, segredar, cochichar); revelam sentimentos, estados de espírito, emoções (por exemplo: gemer, suspirar, lamentar-se, explodir, berrar, gritar). Ou seja, os verbos declarativos apresentam um conteúdo implícito.

Dessa maneira, é possível dizer que os verbos delocutivos são, também, valorativos. Valores estes que não são omitidos no livroreportagem. Afinal, embora seja jornalismo também é literatura. E, assim, o jornalista-escritor não se limita a colocar em cena a fala do outro. O faz para encaminhar o leitor a uma determinada conclusão. Em Rota 66, os verbos usados para introduzir o discurso do(s) outro(s) por Barcelos são: 


\begin{tabular}{|c|c|c|c|}
\hline VERBOS/OCORRÊNCIAS & 19 PARTE & 2@ PARTE & 39 PARTE \\
\hline ACALMAR & & p. 218 & \\
\hline ACUSAR & p. 114 & & p.323 \\
\hline ADMITIR & p.78 & & \\
\hline ADVERTIR & & p. 157, p. 159, p. 216 & \\
\hline AFIRMAR & & $\begin{array}{l}\text { p. } 147 \text {, p. } 170 \text {, p. } 177 \text {, p. } 178, \\
\text { p. } 179 \text {, p. } 182 \text {, p. } 216, \text { p.220, } \\
\text { p.239 }\end{array}$ & p.271, p.341, p.348 \\
\hline ALEGAR & & $\begin{array}{l}\text { p. } 154, \text { p. } 180 \text { (2 vezes), } \\
\text { p. } 197, \text { p. } 237\end{array}$ & \\
\hline ALERTAR & p.35 & $\begin{array}{l}\text { p. } 156 \text {, p. } 159, \text { p. } 181, \text { p. } 189, \\
\text { p. } 209 \text {, p. } 218\end{array}$ & $\begin{array}{l}\text { p.342 (2 vezes), p.346 } \\
\text { p. } 260, \text { p. } 265\end{array}$ \\
\hline AMEACCAR & & p. 215 & \\
\hline ARGUMENTAR & & p.211 & \\
\hline AVISAR & p.21, p.25 & p. 159, p. 214, p. 215, p.226 & p.265, p.271, p.298, p.339 \\
\hline BERRAR & p.27 & & \\
\hline BRINCAR & & p. 157 & \\
\hline COCHICHAR & p.29 & & p.313, p.332 \\
\hline COMENTAR & p. 19, p.77 & p. 158, p. 159, p. 215, p. 225 & p.266, p.267, p.334, p.343 \\
\hline CONCLUIR & & p. 197 & \\
\hline DECLARAR & p. 18 & & \\
\hline DESCULPAR-SE & & p. 214 & \\
\hline DIVULGAR & & p. 158 & \\
\hline DIZER & $\begin{array}{l}\text { p. } 16, \text { p. } 19, \text { p. } 23, \text { p.30, p.48 } \\
\text { p.67 }\end{array}$ & p. 159, p. 182, p.202 & $\begin{array}{l}\text { p.271, p.280, p.285, p.287, } \\
\text { p.342 }\end{array}$ \\
\hline EXIGIR & & p. 213 & p.339 \\
\hline EXPLICAR & p.30 (2 vezes) & p. 160, p. 213, p. 225 & $\begin{array}{l}\text { p.264, p.301, p.306, p.307, } \\
\text { p.335, p.341 }\end{array}$ \\
\hline FALAR & p.23, p.28 & & p.302, p.310 \\
\hline GARANTIR & & p. 147, p. 153, p. 182 & p.249, p.348 \\
\hline GRITAR & $\begin{array}{l}\text { p. } 16, p .25, p .26, p .62 \text { ( } 2 \\
\text { vezes) }\end{array}$ & $\begin{array}{l}\text { p.212, p.213, p.215, p.216 } \\
\text { ( } 2 \text { vezes), p.225, p.237 }\end{array}$ & $\begin{array}{l}\text { p.266, p.267, p.270, p.279, } \\
\text { p.299, p.302, p.314 ( } 2 \\
\text { vezes), p.325, p.343, p.347 }\end{array}$ \\
\hline IMAGINAR & p.78 & & \\
\hline IMPLORAR & & p. 219 & p.341 \\
\hline INDAGAR & & p. 189 & p.332 \\
\hline INFORMAR & & p. 147 & \\
\hline INSISTIR & p. 23 & p. 220 & \\
\hline INTERVIR & & & p.343 \\
\hline JURAR & p.27 & & p.326 \\
\hline LEMBRAR & & p. 218 & \\
\hline MURMURAR & p.28 & & \\
\hline OBSERVAR & p.67 & & p.346 \\
\hline ORDENAR & & p. 218 & p.342, p.343 \\
\hline PEDIR & & p. 189, p.219 & \\
\hline PERGUNTAR & p.23, p.31, p.67, p.71 & $\begin{array}{l}\text { p. } 156 \text { ( } 2 \text { vezes), p. } 159, \\
\text { p. } 189, \text { p.213, p. } 215, \text { p. } 219, \\
\text { p. } 220\end{array}$ & p.253, p.265, p.341, p.348 \\
\hline PREVENIR & p.58 & & \\
\hline PROTESTAR & & & p.343 \\
\hline QUESTIONAR & p. 23 & & \\
\hline REGIR & & & p.271, p.325 \\
\hline RELATAR & p.95 & & \\
\hline REPETIR & p.41, p.77, p. 83 & & \\
\hline RESPONDER & p.23 & $\begin{array}{l}\text { p. } 156 \text { ( } 2 \text { vezes), p. } 158, \\
\text { p. } 159 \text { ( } 2 \text { vezes), p.209, } \\
\text { p. } 215, \text { p. } 218, \text { p. } 225\end{array}$ & p.260, p.264, p.266, p.343 \\
\hline RETRUCAR & p.31 & p.213, p.218 & \\
\hline REVELAR & $\begin{array}{l}\text { p.20 (2 vezes), p.61, } \\
\text { p.79,p.89 }\end{array}$ & p. 184 & p.340 \\
\hline SUGERIR & & p. 218 & p.253, p.298, p.301, p.332 \\
\hline VIBRAR & & p.220, p.221 & \\
\hline
\end{tabular}


Acusar, alertar, ameaçar, berrar, exigir, gritar, ordenar e revelar são exemplos de verbos usados por Barcellos e que, implicitamente, colocam em cena julgamentos, ou melhor, posicionamentos. Assim como o discurso relatado que em Rota 66, em alguns momentos, tem como função explicitar e/ou contrapor o posicionamento do jornalista-escritor e o da Polícia Militar.

Posicionamentos estes que, numa perspectiva de analista do discurso, considero como formações discursivas e formações ideológicas. FDs e Fls que, também, estão não apenas na forma de discurso relatado. Acredito que, ao informar, o jornalista-escritor não apenas relata/narra os fatos, mas também, se posiciona e, nesse momento, confirma filiações ideológicas na forma de informações. Porém, esse é um assunto para uma próxima conversa.

\section{Bibliografia}

BARCELLOS, Caco. Rota 66 - a história da polícia que mata. Rio de Janeiro/São Paulo: Record, 2003.

BENITES, Sônia Aparecida Lopes. Contando e fazendo a história - a citação no discurso jornalístico. Bela Vista/Assis: Arte \& Ciência/Núcleo Editorial Proleitura, 2002.

COSSON, Rildo. Romance-reportagem: o império contaminado. In: CASTRO, Gustavo de; GALENO, Alex (Orgs.). Jornalismo e Literatura - a sedução da palavra. São Paulo: Escrituras, 2002. p.57-70.

INDURSKY, Freda. A Fala dos Quartéis e as Outras Vozes. Campinas: Editora da Unicamp, 1997.

LIMA, Edvaldo Pereira. O que é livro-reportagem. São Paulo: Brasiliense, 1998.

MAINGUENEAU, Dominique. Análise de Textos de Comunicação. 3.ed. São Paulo: Cortez, 2003.

Elementos de lingüística para o texto literário. São Paulo: Martins Fontes, 2001.

NOVO MANUAL DA REDAÇÃO - Folha de S. Paulo. 4.ed. São Paulo: Folha de S. Paulo, 1994. $331 \mathrm{p}$.

RISSO, Mercedes Sanfelice. A representação da fala dos personagens em Fogo Morto (estudo literário e lingüístico). Tese (Doutorado em Letras Clássicas e Vernáculas) - Universidade de São Paulo, São Paulo, 1978.

SATO, Nanami. Jornalismo, literatura e representação. In: CASTRO, Gustavo de; GALENO, Alex (Orgs.). Jornalismo e Literatura - a sedução da palavra. São Paulo: Escrituras, 2002. p.29-45. 